\title{
De Profundis, valsa lenta, o testemunho (?) de Cardoso Pires
}

M aria Luiza Scher Pereira*

* Universidade Federal de J uiz de Fora. 
Comigo me desavim,

Fui posto em grande perigo:

Não posso viver comigo,

Não posso fugir de mim.

Sá de Miranda

No interior can be made safe from

the incursion of the alien other.

Martin J ay

Neste livro, de 1997, J osé Cardoso Pires (1925-1998) apresenta o relato da doença que o acometeu em 1995. No episódio, o escritor perdeu temporariamente a memória e teve afetada sua capacidade de fala e de comunicação. Superada a fase aguda do acidente vascular cerebral, recupera essas habilidades e, dois anos depois, escreve o texto que ele chama de "testemunho" (p. 77), "comunicação de circunstância", e "apontamento pessoal"(p.79).

Um texto de testemunho é uma novidade no conjunto da obra literária de Cardoso Pires, e é inaugural nesse autor que, embora tenha sempre se renovado criativamente dentro do gênero, jamais se afastou, contudo, do modelo canônico da narrativa ficcional.

U m dos traços dessa nossa época pós-moderna parece ser a revalorização do biográfico, do pessoal e do subjetivo, enfim da experiência privada, como um fator de deslocamento do privilégio do ficcional, até agora tido como a forma literária hegemonicamente consagrada e legitimada pelos estudos disciplinares da área. 
Segundo L eonor Arfuch, no artigo "E spacio biográfico e experiencia estética", observa-se hoje, "frente ao desvanecimiento de verdades y utopías", uma espécie de "ressurrección o retorno del autor, (...) una fuerte acentuación de la experiencia que parece ganar terreno a la mera experimentación formal. (...) Así, más que un trabajo de infracción o erosión al interior de los géneros habría tendencia a un movimiento de fuera de género, que también se expresa como inquietud académica."

E acrescenta: “Existencia, autor, vivencias, contenidos, identidades... Palabras contra las quales hemos librado combates encarnizados pero que vuelven - es verdad que siempre diferentes - a suscitar hoy nuestra atención." (1998:41)

Nesse caso, tudo o que era até então considerado marginal pelos estudos literários, ganha espaço no trabalho acadêmico, e a obra literária passa a ser objeto de um outro tipo de exercício crítico e lida sob nova perspectiva teórica, o que a coloca em diálogo com o não literário, como as correspondências, depoimentos, diários íntimos e manifestações textuais afins, que, de resto, deslocam também o autor de sua posição convencional de literato.

Pelo testemunho se exibe a subjetividade banida da escrita literária pelo império do texto autônomo da ficção, pela assepsia da literariedade.

No texto "T he margin at the center", publicado na coleção de trabalhos teóricos sobre discurso testemunhal intitulada The real thing, J ohn B everley diz que o testemunho pode ser assim compreendido:

... a narrative (printed as opposed to acoustic) form, told in the first person by a narrator who is also a real protagonist or witness of the event he or she recounts, and whose unit of narration is usually a "life" or a significant life experience. (...) The situation of narration in testimonio has to involve a urgency to comunicate, a problem of repression, poverty, subalternity, imprisonment, struggle for survival, and so on.(...) Unlike the novel, testimonio promises by definition to be primarily concerned with sincerity rather than literariness. (B everley: 1996,24/26)

É claro que, embora aparentemente se estejam tornando imprecisos os limites entre o privado e o público, pela exibição do pessoal e exposição da experiência, não se trata de uma volta à crença na sinceridade ingênua, mas de uma espécie de "necesidad compensatoria de reposición del sujeto, (...) entramada en la intersubjetividad de lo social" (Arfuch:op.cit,42).

Trata-se, principalmente, acreditamos nós, de desafiar o sistema literário canônico pela apresentação de um tipo de discurso que se poderia chamar de "subalterno", usando a acepção de Homi Bhabha (1998), em relação ao discurso 
literário, hegemonicamente privilegiado como único objeto da crítica acadêmica e da teoria literária estruturalista.

Posto isso, diante desse texto que Cardoso Pires apresenta como testemunho de um episódio de vida, onde há a exposição pública de um drama privado, perguntamo-nos se o autor, antenado com a tendência contemporânea de deslizamento de fronteiras de gênero, de disciplinas, de saberes, estaria se aproveitando da experiência pessoal da doença para experimentar também uma nova possibilidade de escrita.

A partir de um levantamento de diversos estudos feitos do famoso texto "T he uncanny", que Freud publica em 1919, o crítico americano Martin J ay chama a atenção para o fato de que a idéia do "uncanny" (isto é, do estranho) éfuncional à compreensão dos produtos de cultura das sociedades contemporâneas, marcadas pela pós-modernidade e pela "current obsession with the troubled interface between history and memory"(J ay:1998,163).

Traduzido do termo alemão Unheimlich, o termo "uncanny", em sentido amplo, remete a alguma coisa que é ao mesmo tempo estranha e familiar, ou estranhamente familiar, como uma vaga sensação de reconhecimento de um lugar ou de uma experiência nunca visitado ou nunca vivida. Por sua duplicidade, diz Martin Jay, "the experience of the uncanny is itself both disturbing and pleasurable"(id.ib:158)

O "uncanny", de modo geral, relaciona-se a fulgurações ou sensações de reconhecimentos, memórias, sentimentos que retornam, apesar de não terem nunca sido vivenciados. "Uncanny" seria então o que emerge do não-lugar, como sintoma de uma falta, como linguagem que preenche o vazio, linguagem que, contudo, se constrói como dissonância, como alteridade, ou, ainda, como subalternidade.

A referência ao "uncanny" vem a propósito desse relato testemunhal de Cardoso Pires, permanentemente atravessado por aquele outro estranho que desafia o eu racional e o obriga a escrever sobre esse desafio.

O testemunho de Cardoso Pires, pode ser compreendido como um estranho ("uncanny") texto, e como um discurso subalterno, na medida em que é ao mesmo tempo um testemunho e um falso testemunho, um discurso que contém o eu que se pretende razoável e o outro, seu duplo, que o confronta com sua desrazão.

\section{De Profundis: o Eu e Outro de mim}

A citação, no título do livro, das primeiras palavras do Salmo 129 leva-nos a refletir sobre o modo como Cardoso Pires se relaciona com a doença e, consequentemente, com a cura. 0 salmo 129, conhecido como o sexto penitencial, 
pertence à série de sete salmos dedicados à confissão das culpas e ao pedido de salvação. Pela articulação construída nele entre pecado e morte, e entre perdão e salvação, este salmo é também rezado como oração fúnebre, nas cerimônias religiosas, onde se invoca o perdão e a consequente salvação da alma do morto.

A partir disso, verifica-se que Cardoso Pires relaciona a sua patologia, ou as lesões decorrentes dela, ao mal e à morte, como indicam as expressões "morte branca”, “golpe de azar", “apagamento", “desertificação”, “ilha de náufragos", “loucura”, “cegueira”, “caos", usadas para a sua condição de desmemória e de afasia.

Como se vê, todos esses termos contrastam com a idéia de que a cura seria a salvação, pelo retorno da vida, da sorte, da luz, e, enfim, da razão.

O cartesianismo seria, então, pelo menos em princípio o fio condutor desse relato, uma vez que o seu autor, agora redimido, ter-se-ia reapossado de todas as defesas contra o mal da doença. Essa tentativa de provar, com o livro, que está recuperado imprime no texto-testemunho uma marca de identidade, a do intelectual, capaz de produzir um relato intelectualmente competente do seu estado de doença.

Também com o doente que então foi, Cardoso Pires mantém uma relação dolorosamente negativa, que a expressão "farrapo de indivíduo" ( p.38) exemplifica. A dificuldade de identificação com o doente expressa-se, mais claramente, na insistente diferenciação entre o Eu e o Outro, que percorre todo o texto.

Com curiosidade, às vezes com compaixão, mas sempre com pretenso distanciamento, o autor do relato refere-se a si próprio, quando doente, como "ele, o outro": "o outro de mim" ( p.26 e p.50); o "outro sem nome e sem memória" (id.); o "meu homem sem memória" (p.40) é aquele de quem o eu relata as "respostas estropiadas" ( p.34) e o "insólito dos desacertos"(p. 35) . O distanciamento pretendido entre o eu saudável e o ele doente se estrutura, finalmente, na forma narrativa, em que o uso da $3^{a}$ pessoa transforma esse ele na dramatis persona do relato do eu.

Durante todo o relato, o eu apresenta-se como um escritor, "sujeito de livros e de escrita" (p.66), portanto como alguém que domina o código e usa a linguagem com os recursos que a prática intelectual lhe oferece. Assim, confronta abertamente a alteridade em que se constitui o outro, que "tinha perdido a inteireza da fala (...) , os valores da grafia e ficara analfabeto de mim e da vida" (p.65).

Esse estranho outro situa-se numa espécie de não-lugar, chamado pelo autor de "fundo da razão perdida", por oposição ao espaço ocupado pelo escritor, referido como o "alto dessa página em que estou a reconstituir passo a passo esse Outro..."(p.33) 
Para o escritor, a perda da memória e da consciência da razão é como a morte, mas a perda da capacidade de escrever é ainda mais apavorante. O medo dessa perda povoa as margens do texto como fantasmas que se representam nas suas ilustrações.

A morte está na fotografia da "mariposa-caveira", uma espécie de borboleta cujo corpo é um esqueleto humano, que segundo o autor os mexicanos adotaram como figurante de procissões de carnaval. O hibridismo da figura na fotografia convoca o estranho e representa o fantasma da morte.

A outra ilustração é um desenho de $G$ unther $G$ rass, que parece o sintoma do medo de uma espécie de castração do escritor. A idéia fantasmática da impossibilidade de voltar a escrever toma a forma do sapo monstruoso que tem diante da pata dianteira uma caneta-tinteiro, caída e inútil. O título do desenho - "Maus presságios" - também é sugestivo do medo dessa incapacidade de escrita.

R ecordando que para F reud a emergência do "uncanny" está de alguma forma relacionada com o medo da castração, é significativo observar que é com um termo que semantiza perda que Cardoso Pires refere-se a si próprio, quando doente: "fui desapossado das minhas relações com o mundo e comigo próprio"( p.25). Essa perda de identidade desdobra-se progressivamente na perda da identidade do escritor, que é uma espécie de castração: “...era o ex-autor de livros” (p.51); "nem voz nem escrita e nem leitura tão pouco. Morte cerebral..." (p.33).

A castração simbólica aparece claramente no adjetivo "estropiado", ou seja deformado, mutilado, com que se refere à linguagem do doente: "respostas estropiadas e o rosto eternamente apontado para uma vastidão qualquer" ( p.34) .

R egistrando a desrazão da linguagem distorcida do outro, o eu se espanta com a criação da estranha palavra "simosos" para nomear objetos vários como gilete ou óculos, ou com o uso também estranho de "cachimbo" para identificar os chinelos de quarto.

O "uncanny" aqui manifesta-se como retorno à linguagem primitiva ( “lalangue”, na concepção de L acan), anterior à separação definitiva entre as palavras e as coisas. A fala distorcida, o aparentemente aleatório, o inventado, denunciam a emergência do subalterno que, com sua linguagem "uncanny", escapa ao controle da razão, atravessa a fronteira do código, perturbando todo o sistema. Voltando à segunda epígrafe desse trabalho, teríamos aí a incursão do inevitável "alien other" de que fala Martin J ay.

\section{Valsa lenta: distanciamentos e aproximações}

No episódio em que o autor do relato refere-se à "desvairada nomenclatura que ele (o doente) atribuía aos objetos" ( $p .37$ ) temos, aparentemente, um mo- 
mento de forte antagonismo entre o são e o doente. Contudo, é aí que temos também a entrada no relato desse outro que aparece progressivamente como um ser estranhamente familiar ao eu.

E $m$ dois momentos, o eu registra do outro reações que ele encarece tão somente porque lhe parecem ser a manutenção de uns resquícios de razão. No entanto, nesses momentos também se torna flexível a barra da separação total entre ambos.

No primeiro episódio, o doente dá à neurologista uma resposta levemente irônica a um teste simples de subtração:

“Onze menos nove quantos são?". R esposta: “Nada, senhora doutora. Qualquer coisa noves fora é nada" (p.39). A infância, o fragmento de memória, a brincadeira de tabuada irrompem, trazendo para o relato a confusão entre ele e o eu que neste momento, oferece, de fato, um testemunho pessoal: “... E ra eu há anos, há séculos, na Escola Primária do Largo do Leão, em Lisboa, a declamar o "nove, noves fora, nada". (p.39) A aproximação entre o eu e o outro, seu duplo, está marcada no deslizamento textual da $3^{a}$ para a $1^{\text {a }}$ pessoa.

Nesse movimento de alternância, o eu comemora no episódio acima o uso da ironia pelo outro, que o surpreende por ser tão estranhamente familiar: apesar de ser, segundo sua avaliação, uma "ironia coitada", era "de qualquer forma uma ironia". (p. 38)

Em outro momento, o doente lê de trás para frente a palavra BANHOS e, embora fugazmente, estranha sua forma invertida. A confusão entre esse ele doente e o eu que tenta se distanciar estabelece-se, mais uma vez, no nível mesmo da frase: "Inacreditável. Eu, o Outro de mim, em viagem de passos perdidos e a interrogar-me se não estaria a caminhar para a loucura." (p. 50)

Nos dois casos, o eu e o ele se aproximam quando o doente se mostra menos alheio ao razoável e mais apto ao exercício da reflexão ou da consciência. Mas, também em ambos os casos, o reconhecimento do outro como familiar se dá pela relação de ambos com soluções de linguagem.

A presença do estranho outro (o "uncanny") e de sua linguagem própria (o discurso subalterno) atravessa todo o relato, ora em rota de distanciamento, ora em rota de aproximação. Na passagem abaixo, vemos a autoridade com que o eu analisa e interpreta a linguagem do outro, distanciando-se dele:

'Eu tenho filhos, não tenho?' pergunta ele à E dite. (E u. U ma vez mais o sujeito solitário, repare-se.) 'Como é que eles se chamam?'

'Temos duas filhas. A Ana e a R ita', responde ela.

'Rua?'

'Não. Rita', diz a E dite. 
E ele: 'Pois, Rua.' (Pensava ter dito Rita, é evidente.)

(p.42)

Na passagem seguinte, já se verificam o reconhecimento e a surpresa de um certo tipo de aproximação entre ambos:

Demoro-me um pouco sobre as fotocópias da caligrafia desse homem nos testes da fala e da escrita (...). Dessa caligrafia enlouquecida (...) o J se mantém reconhecível. O J de J osé. A letra menos espontânea da minha identificação. (p.39)

É nesse momento que o outro mais desafia o eu, e é a partir desse confronto que se percebe a ambiguidade do caráter testemunhal, com que o livro se apresenta ao leitor. Contudo, é também nessa relação de rejeição e atração pelo e com o doente que as sensações de algo estranhamente familiar ("uncanny") se manifestam.

No movimento entre o afastamento e a flexibilização da distância entre o eu razoável e o outro doente, temos a construção de um terceiro elemento que se dá na linguagem do relato: o mesmo e o outro se opõem mas também se somam; o eu e o ele são o mesmo e o outro ao mesmo tempo, dentro e fora do relato. O próprio relato está dentro e fora das fronteiras de gênero: nem é depoimento ingênuo, nem é só peça literária, encomiástica da razão e da vigilância crítica do intelectual redimido da loucura e do caos.

E scrito para preencher o lugar da falta - decorrente da perda da memória e da sanidade - o testemunho de Cardoso Pires é, mais que um depoimento e mais que uma peça literária, um texto que contém frestas de ambiguidades e mesmo de silêncios, decorrentes da perplexidade provocada pela novidade que a doença traz.

F inalmente, pode-se ler a organização do livro também como um sintoma da tentativa de preencher vazios e descontinuidades. O prefácio foi solicitado pelo autor a um médico que, contudo, abdica da análise do caso clínico e, na forma privada e pessoal de "carta a um amigo novo", dialoga, não com o paciente, mas com o homem que, com emoção, comemora a recuperação de seus bens pessoais, referências afetivas e memórias familiares.

O posfácio é do próprio autor e, embora se inicie com mais uma tentativa de interpretar o caso e o relato dele, termina com um pessoalíssimo agradecimento aos médicos que o atenderam no Hospital Santa M aria, de Lisboa, fato banal no cotidiano das vidas comuns, como atestam mensagens desse tipo frequentemente publicadas nos jornais.

Assim, acreditamos que este livro vem se somar aos outros não apenas para figurar numa possível Obra Completa do autor, nem apenas para constar como 
uma diferença do resto, por ser um texto narrativo incomumente testemunhal no conjunto da obra de Cardoso Pires.

Preferimos pensar que De Profundis, valsa lenta sugere novas possibilidades de leitura da obra literária de Cardoso Pires, e, ao mesmo tempo, provoca uma reflexão sobre os desafios que se impõem ao crítico literário, nesses tempos de quedas de certezas e de redefinição de cânones e hegemonias, ou, para citar de novo Martin J ay, nesses "uncanny nineties" em que estamos vivendo.

\section{R eferências Bibliográficas}

ARFUCH, Leonor. Espacio biográfico y experiencia estética. In ANTELO, R. e outros. Declínio da arte/ascensão da cultura. F lorianópolis, Livraria e E ditora O bra J urídica, 1998.

BEVERLEY, J ohn. The margin at the center. In GUGELBERGER, G.M. The real thing. Testemunhal discourse and Latin America. Duke University Press, 1996.

BHABHA, Homi. DissemiNação: $O$ tempo a narrativa e as margens da nação moderna. $O$ local da cultura. Trad. M yriam Á vila e outros. B elo Horizonte, E ditora da UF M G, 1998.

FREUD, Sigmund. Lo siniestro. Obras completas de Sigmund Freud. Tomo III. 4 ed. M adrid, E ditorial Biblioteca Nueva, 1981.

J AY, M artin. The uncanny ninities. Cultural Semantics. Keywords of our ti me. The University of M assachusetts Press, 1998.

PIRES, J osé Cardoso. De Profundis, valsa Ienta. Rio de J aneiro, B ertrand do Brasil, 1998.

Agosto de 1999. 
